\title{
Casualty-a cause for concern
}

\author{
N. R. M. KAY \\ F.R.C.S. \\ Resident Surgical Officer, \\ Robert Jones and Agnes Hunt Orthopaedic Hospital, Oswestry
}

To those familiar with the Robert Jones and Agnes Hunt Orthopaedic Hospital it may at first seem a little incongruous that a hospital whose past reputation was founded on 'cold orthopaedics' should concern itself with problems of trauma and the casualty department. The reason is not because we are concerned about the little trauma we receive from the surrounding countryside but because all of the resident staff in training have, at some time, worked in casualty departments, and are aware of the problems. Moreover, most of the residents are aware that their future responsibilities will probably entail supervision of these departments as well as the clinical responsibility for treating many of the patients admitted via the casualty department.

The discussion at the British Orthopaedic Conference in Belfast (1971) was therefore of considerable interest, and we viewed with a little alarm some of the 'impressions' we gained at the meeting, for it appeared to us that there was no coherent policy emerging from the ranks of the orthopaedic surgeons. Discussion and inquiry continued within the Mess at Oswestry and it soon became obvious that amongst the resident staff there was a wealth of practical experience gained from working in many different types of casualty departments throughout England. Moreover, all of us had been 'drafted' into the casualty department to fulfil the regulations for the examination for Fellowship of the Royal College of Surgeons, but, as far as we could ascertain no generation of senior registrars had been asked what their views were on the existing casualty departments and whether in fact they wanted to be involved with the casualty departments on being appointed as consultants. We also noted that despite the introduction of an approved training programme which laid a considerable emphasis on training in traumatic surgery, if an orthopaedic consultant had little or no interest in the day-to-day running of this department then the casualty department very often merited the description of 'the hospital Cinderella'.

It was against this background that we decided to convene a National Conference, primarily of senior registrars at present committed to a career in accident and orthopaedic surgery. We planned that such a conference would have three major objectives:

\section{(A) The dissemination of information}

To this end we have invited representatives not only as speakers but also to be present at the conference from the various organizations interested in the casualty departments; Dr J. M. Bainbridge from the Department of Health and Social Security, Mr L. W. Aldrige from the Birmingham Regional Hospital Board, Mr D. B. Caro from the Casualty Surgeons Association, Mr F. C. Durbin from the British Orthopaedic Association, and Dr T. Cull representing the general practitioners.

(B) To clarify the opinions of the men in training in accident and orthopaedic surgery

We hope this will emerge from the discussion groups and the general discussion of the speakers' contributions.

\section{(C) To suggest patterns of management of the 'casualty services'}

In this respect the contribution of $\mathrm{Mr} \mathrm{R}$. A. Denham and Mr R. A. Elson cannot fail to act as a stimulus.

It would be naive to imagine that one single solution will emerge from this conference which is applicable to all the hospitals throughout the country. What we do all sincerely believe is that there should be one goal, namely, the organization of the accident services throughout the country so that they will be efficient and yet retain the humanity essential in all branches of medicine. If we can only point several ways of reaching this objective and, by discussion with the interested parties indicate some of the problems, we shall establish a dialogue between all the organizations represented here today. Then, our combined efforts working towards the same mutually defined goal must achieve success. 